\title{
Updates in oncology
}

\author{
Jean-Paul Sculier, Anne-Pascale Meert and Thierry Berghmans
}

Affiliations: Service des Soins Intensifs et Urgences Oncologiques, Unité de recherche en oncologie thoracique, Institut Jules Bordet, Centre des Tumeurs de l'Université Libre de Bruxelles (ULB), Brussels, Belgium.

Correspondence: J-P Sculier, Institut Jules Bordet, Rue Héger-Bordet, 1, B-1000 Brussels, Belgium. E-mail: sculierabordet.be

ABSTRACT The objective of this review is to report the Clinical Year in Review proceedings in the field of thoracic oncology that were presented at the 2013 European Respiratory Society Annual Congress in Barcelona, Spain. Various topics were reviewed, including: epidemiology, screening, histology, and treatment of nonsmall cell lung cancer and small cell lung cancer.

0 @ERSpublications

Lung cancer increasing in females; screening based on risk selection; doublet platinum-based chemotherapy recommended http://ow.ly/sjbR6

\section{Epidemiology}

European cancer mortality predictions for lung cancer in 2013 report a continuing reduction in males, but a continuing increase in females [1]. For the first time in females, mortality from lung and breast cancers should be equivalent. In 2013, age-standardised mortality rates per 100000 are estimated to be 37.1 in males and 13.9 in females for lung cancer.

A US epidemiological study [2] has confirmed the data of the UK doctors' cohort [3]. The authors obtained smoking and smoking-cessation histories from 113752 females and 88496 males who were interviewed between 1997 and 2004. These data were related to the causes of deaths that occurred by the end of 2006 (8236 deaths in females and 7479 in males). The rate of death from any cause among current smokers was approximately three times that among those who had never smoked. The hazard ratios for females and males were 3.0 (99\% CI 2.7-3.3) and 2.8 (99\% CI 2.4-3.1), respectively. Life expectancy was shortened by $>10$ years among the current smokers compared with those who had never smoked. Adults who had quit smoking 25-34, 35-44 or 45-54 years of age gained approximately 10, 9 and 6 years of life, respectively, compared with those who continued to smoke. This is in complete agreement with the UK observation.

Temporal trends in mortality across three time-periods (1959-1965, 1982-1988 and 2000-2010) were compared in terms of absolute and relative risks according to sex and self-reported smoking status in two historical and five pooled contemporary US cohort studies [4]. For females who were current smokers compared with females who had never smoked, the relative risk of death from lung cancer was 2.73, 12.65 and 25.66 in the 1960s, 1980s and contemporary cohorts, respectively; corresponding relative risk for male current smokers compared with males who had never smoked was 12.22, 23.81 and 24.97 over the same time-periods, respectively. As in Europe, the risk of death by lung cancer from cigarette smoking in the USA continues to increase among females and the increased risks are now nearly identical for males and females; however, this is not the case in Europe.

By pooled analysis, the International Lung Cancer Consortium determined the associations between prior lung diseases and the occurrence of lung cancer [5]. The analysis included 17 studies with 24607 cases and

Received: Dec 122013 | Accepted after revision: Dec 202013

Conflict of interest: None declared.

Provenance: Submitted article, peer reviewed.

Copyright OERS 2014. ERR articles are open access and distributed under the terms of the Creative Commons Attribution Non-Commercial Licence 3.0. 
81829 controls, mainly conducted in Europe and North America between 1984 and 2011. A history of emphysema, chronic bronchitis, tuberculosis and pneumonia conferred relative risks of lung cancer of 2.44 (95\% CI 1.64-3.62 (16 studies)), 1.47 (95\% CI 1.29-1.68 (13 studies)), 1.48 (95\% CI 1.17-1.87 (16 studies)) and 1.57 (95\% CI 1.22-2.01 (12 studies)), respectively. Among never-smokers, elevated risks were observed for emphysema, pneumonia and tuberculosis. Thus, previous lung diseases influence lung cancer risk independently of tobacco use and these diseases should be taken into consideration for assessing individual risk.

The effect of autoimmune diseases on lung cancer risk has been assessed in a very large Swedish registry [6], with a total number of 402062 autoimmune disease patients and an accumulated 4.8 million person-years at risk, with a mean follow-up of 11.9 years. The highest standardised incidence ratios and standardised mortality ratios, respectively, were seen after discoid lupus erythematosus (4.71 and 4.80), polymyositis/ dermatomyositis (4.20 and 4.17), systemic lupus erythematosus (2.47 and 2.69), rheumatic fever (2.07 and 2.07 ) and systemic sclerosis (2.19 and 1.98). Standardised incidence ratios were decreased in pernicious anaemia patients $(0.70)$. The overall standardised incidence ratios increased after autoimmune disease for all histological types, but mostly for small cell carcinoma (1.43) and squamous cell carcinoma (1.40). Autoimmune disease did not influence overall survival but some autoimmune diseases (mainly after amyotrophic lateral sclerosis and discoid lupus erythematosus) appeared to impair survival in small cell carcinoma. Those data suggest that the autoimmune process can contribute to lung cancer susceptibility.

Air pollution has also been assessed by a pooled prospective analysis of data obtained by the European Study of Cohorts for Air Pollution Effects, using data from 17 cohort studies based in nine European countries [7]. The cohort included 312944 members for a total 4013131 person-years at risk. During the follow-up period (mean 12.8 years), 2095 incident cases of lung cancer were diagnosed. The meta-analysis showed a statistically significant association between risk for lung cancer and particulate matter $<10 \mu \mathrm{m}$ (PM10) (hazard ratio (HR) $1.22\left(95 \%\right.$ CI 1.3-1.45) per $\left.10 \mu \mathrm{g} \cdot \mathrm{m}^{-3}\right)$. The same increments of PM10 and PM2.5 were associated with HRs for adenocarcinomas of the lung of 1.51 (95\% CI 1.10-2.08) and 1.55 (95\% CI 1.05-2.29), respectively. An increase in road traffic of 4000 vehicles per $\mathrm{km}$ per day within $100 \mathrm{~m}$ of the residence was associated with a HR for lung cancer of 1.09 (95\% CI 0.99-1.21). In October 2013, the International Agency for Research on Cancer (IARC) classified outdoor air pollution as carcinogenic to humans (Group 1).

\section{Screening}

A systematic review of lung cancer screening using low-dose computed tomography (LDCT) has been reported by a group of US medical societies [8], taking into account the recently published National Lung Screening Trial (NLST). Of the eight identified randomised trials and 13 cohort studies, only three randomised studies provided evidence on the effect of LDCT screening on lung cancer mortality. The main results are summarised in table 1 [9-13]. The NLST, which is the only trial to show a significant effect on lung cancer mortality, has such a large number of subjects that it strongly influences any type of aggregation. The conclusions of the authors are that "LDCT screening may benefit individuals at an increased risk for lung cancer, but uncertainty exists about the potential harms of screening and the generalizability of results".

\begin{tabular}{|c|c|c|c|}
\hline & DANTE [9] & NSLT $[10,11]$ & DLCST $[12,13]$ \\
\hline Control & Usual care & Chest radiograph & Usual care \\
\hline \multicolumn{4}{|l|}{ Participants screened } \\
\hline Control arm & 1276 & 26722 & 2052 \\
\hline LDCT & 1196 & 26732 & 2052 \\
\hline \multicolumn{4}{|l|}{ Overall mortality } \\
\hline Relative risk $(95 \% \mathrm{CI})$ & $0.97(0.80-1.20)$ & $0.93(0.86-0.99)$ & $1.19(1.01-1.40)$ \\
\hline Number needed to screen to prevent one event & 635 & 219 & NR \\
\hline \multicolumn{4}{|l|}{ Lung cancer-specific mortality } \\
\hline Relative risk $(95 \% \mathrm{CI})$ & $0.97(0.71-1.32)$ & $0.80(0.73-0.93)$ & $1.15(0.83-1.61)$ \\
\hline Number needed to screen to prevent one event & 954 & 320 & NR \\
\hline
\end{tabular}

Data are presented as n, unless otherwise stated. NLST: National Lung Screening Trial; DLCST: Danish Lung Cancer Screening Trial; NR: not reported. Data from [8]. 
The data of the NSLT were analysed according to the risk of lung cancer death [14]. Taking into account the demographic, clinical and smoking characteristics of the participants, the authors obtained a prediction model with which they divided the population into quintiles of 5-year risk of lung cancer death. In the lowest quintile, the number needed to screen to avoid one death by lung cancer was 5276, while in the highest quintile it was 161 . These data need to be interpreted within the context of LDCT screening in the NLST, limiting extrapolation to alternative screening and follow-up schedules. Results from European trials such as NELSON, where a better control of smoking habits of the participants has been performed, are expected to provide better evidence in favour of not using LDCT screening.

\section{Histology}

The prognostic impact of the novel International Association for the Study of Lung Cancer/American Thoracic Society/European Respiratory Society proposal for an architectural classification of invasive pulmonary adenocarcinomas [15] was assessed in a retrospective German study [16] with 500 cases. Overall survival differed significantly between lepidic (78.5 months), acinar (67.3 months), solid (58.1 months), papillary (48.9 months) and micropapillary (44.9 months) predominant adenocarcinomas. The prognostic impact on survival and disease-free survival was independent of stage and adjuvant radiotherapy and/or chemotherapy. These data strengthen this classification.

The same group analysed the associations between histomorphological adenocarcinoma growth patterns (lepidic, acinar, papillary, micropapillary and solid) and the radiological aspects on chest computed tomography in 174 resected pulmonary adenocarcinomas [17]. Margin configuration and solidity/ground-glass opacity were associated with distinct histomorphological adenocarcinoma growth patterns. Solid-predominant adenocarcinomas usually had smooth margins and were also solid on CT scans, while lepidic-predominant tumours had no predominant margin pattern, were located in the periphery, showed a positive bronchogram and were frequently associated with solidity/ground-glass opacity. In addition, non-spherical tumour growth was a negative predictor of overall and disease-specific patient survival.

\section{Nonsmall cell lung cancer treatment \\ Surgery}

The effect of procedural volume and surgeon specialty on outcome of lung resections for cancer has been assessed in a systematic review of the literature with meta-analysis [18]. 19 studies published in English over the past 20 years were selected. The meta-analysis was in favour of high-volume hospitals regarding postoperative mortality (OR 0.71, 95\% CI 0.62-0.81), but not for survival (OR 0.93, 95\% CI 0.84-1.03). Surgeon volume showed no significant effect on outcome. General surgeons had significantly higher mortality risks than general thoracic (OR $0.78,95 \%$ CI $0.70-0.88$ ) or cardiothoracic surgeons (OR 0.82 , 95\% CI 0.69-0.96). A minimal annual volume of resections for better outcome could not be identified [18]. More data are necessary for performing evidence-based recommendations.

\section{Radiotherapy}

A randomised trial conducted in Japan assessed combined chemoradiotherapy in elderly patients with locally advanced nonsmall cell lung cancer (NSCLC) [19]. A total of 200 patients aged $>70$ years (median (range) 77 (71-93) years) with unresectable stage III NSCLC were randomly assigned to chemoradiotherapy (60 Gy plus concurrent low-dose carboplatin given at $30 \mathrm{mg} \cdot \mathrm{m}^{2}$ per day, 5 days a week for 20 days) or radiotherapy alone. There was a statistically significant improvement in overall survival (HR 0.68, 95\% CI 0.47-0.98) with median survival of 22.4 months and 16.9 months, respectively, for the chemoradiotherapy and radiotherapy alone groups. More patients had grade 3-4 haematological toxicity with chemoradiotherapy with which three infections were also more common. Incidences of grade 3-4 pneumonitis and late lung toxicity were similar between groups. There were seven treatment-related deaths: three (3\%) out of 100 patients in the chemoradiotherapy group and four (4\%) out of 100 in the radiotherapy group. This important study supports the administration of combined chemoradiotherapy in patients aged $>70$ years.

\section{Chemotherapy for advanced disease}

Although chemotherapy remains the treatment modality for advanced NSCLC in western countries, it is no longer the main topic of clinical trials. Nevertheless, two important academic randomised studies have been published assessing first-line treatment by conventional chemotherapy in the standard patient.

The GOIRC (Gruppo Oncologico Italiano di Ricerca Clinica) investigators assessed two questions in a $2 \times 2$ factorial trial [20]: 1) replacing cisplatin by a non-platinum agent, vinorelbine; and 2) adding a third agent, ifosfamide, in a doublet based on gemcitabine. A total of 417 patients were randomised between October 2001 and July 2006. Adjusted overall survival was in favour of platinum-based regimens compared with 
non-platinum-based regimens with a median of 9.7 months versus 11.3 months $(\mathrm{p}=0.044)$. No statistically significant difference was observed between doublets and triplets. This complex trial provides more evidence in favour of cisplatin-based chemotherapy.

The Norwegian Lung Cancer Study Group compared vinorelbine and gemcitabine versus vinorelbine and carboplatin as first-line treatment of advanced NSCLC [21]. A total of 444 patients were randomised between September 2007 and April 2009. Vinorelbine plus carboplatin did not result in better survival (median survival 6.3 months versus 7.0 months for the non-platinum doublet), but was associated with more grade III/IV nausea/vomiting and grade IV neutropenia. This trial does not support the use of carboplatin-based chemotherapy in advanced NSCLC.

A randomised clinical trial has been conducted in patients with an Eastern Cooperative Oncology Group (ECOG) performance status of 2 [22]. Patients with adequate organ functions were randomly assigned to pemetrexed alone $\left(500 \mathrm{mg} \cdot \mathrm{m}^{2}\right)$ or to carboplatin (area under the curve of 5) and pemetrexed $\left(500 \mathrm{mg} \cdot \mathrm{m}^{2}\right)$. A total of 205 eligible patients were enrolled from eight centres in Brazil and one in the USA from April 2008 to July 2011 . The response rate was significantly better with the doublet $(23.8 \%$ versus $10.3 \%)$, as well as survival (HR 0.46, 95\% CI 0.35-0.63; p<0.001) with median survival of 9.3 months versus 5.3 months and 1 -year survival rates of $40.1 \%$ versus $21.9 \%$. This study does not support the use of single-agent chemotherapy as first-line treatment of advanced NSCLC.

Customised chemotherapy was assessed in the second randomised trial conducted on the topic [23]. The purpose of the study was to determine whether chemotherapy selection based on in situ excision repair cross-complementing 1 (ERCC1) and ribonucleotide reductase regulatory subunit M1 (RRM1) protein levels would improve survival in patients with advanced NSCLC. 183 eligible patients were randomly assigned 2:1 to the trial's experimental arm, which consisted of gemcitabine plus carboplatin if RRM1 and ERCC1 were low, docetaxel plus carboplatin if RRM1 was high and ERCC1 was low, gemcitabine plus docetaxel if RRM1 was low and ERCC1 was high, and docetaxel plus vinorelbine if both RRM1 and ERCC1 were high. In the control arm, 92 patients received gemcitabine plus carboplatin. No statistically significant differences were observed between the experimental arm and the control arm in progression free survival (6.1 months versus 6.9 months) or overall survival (11.0 months versus 11.3 months). The second trial also failed to show a survival advantage with customised chemotherapy.

Maintenance therapy for advanced NSCLC has been assessed in two randomised trials, both, at least partially, supported by the pharmaceutical industry. In the first trial [24], 464 patients without tumour progression after four cycles of cisplatin-gemcitabine were randomly assigned to observation or to gemcitabine $\left(1250 \mathrm{mg} \cdot \mathrm{m}^{-2}\right.$ on days 1 and 8 of a 3 -week cycle) or daily erlotinib $\left(150 \mathrm{mg} \cdot\right.$ day $\left.^{-1}\right)$. Both maintenance strategies resulted in a significant improvement in progression-free survival but not in overall survival. In the second [25], the PARAMOUNT trial, 539 patients with advanced non-squamous NSCLC and no disease progression after four cycles of pemetrexed-cisplatin induction therapy were randomly assigned $(2: 1)$ to maintenance pemetrexed or placebo. Pemetrexed therapy resulted in a statistically significant $22 \%$ reduction in the risk of death (HR 0.78, 95\% CI 0.64-0.96; $p=0.0195$; median overall survival: pemetrexed 13.9 months; placebo 11.0 months). This trial supports the administration of singleagent maintenance chemotherapy if induction treatment is limited to four cycles of chemotherapy.

\section{Tyrosine kinase inhibitors}

Over the past 2 years, tyrosine kinase inhibitors (TKI), which are targeted therapies, have been the subject of multiple randomised clinical trials. These trials, usually conducted for registration purposes, are summarised in table 2. The most important publications will be discussed below.

Four trials compared TKI to chemotherapy as first-line treatment for advanced NSCLC. Two trials were performed in unselected patient populations and the other two in patients with an activating epidermal growth factor receptor (EGFR) mutation. The updated results of a Japanese study comparing gefitinib with carboplatin-paclitaxel for chemotherapy-naïve NSCLC with sensitive EGFR gene mutations showed no significant difference in overall survival despite a much better progression-free survival in the gefitinib arm [26]. This result is probably due to high crossover use of gefitinib in the chemotherapy group. Another trial compared afatinib, a new TKI, to the doublet cisplatin+pemetrexed in patients with metastatic adenocarcinoma also with EGFR mutations [29]. Similar results were obtained, i.e. much better progression-free survival in the TKI group but no improvement in overall survival, with a similar explanation. Afatinib is now registered in the European Union.

In the TORCH (Tarceva or Chemotherapy) trial [28], unselected patients with advanced NSCLC were randomised to either first-line erlotinib followed at progression by cisplatin-gemcitabine or the standard inverse sequence. The study, performed with a non-inferiority design, was terminated early because first-line 


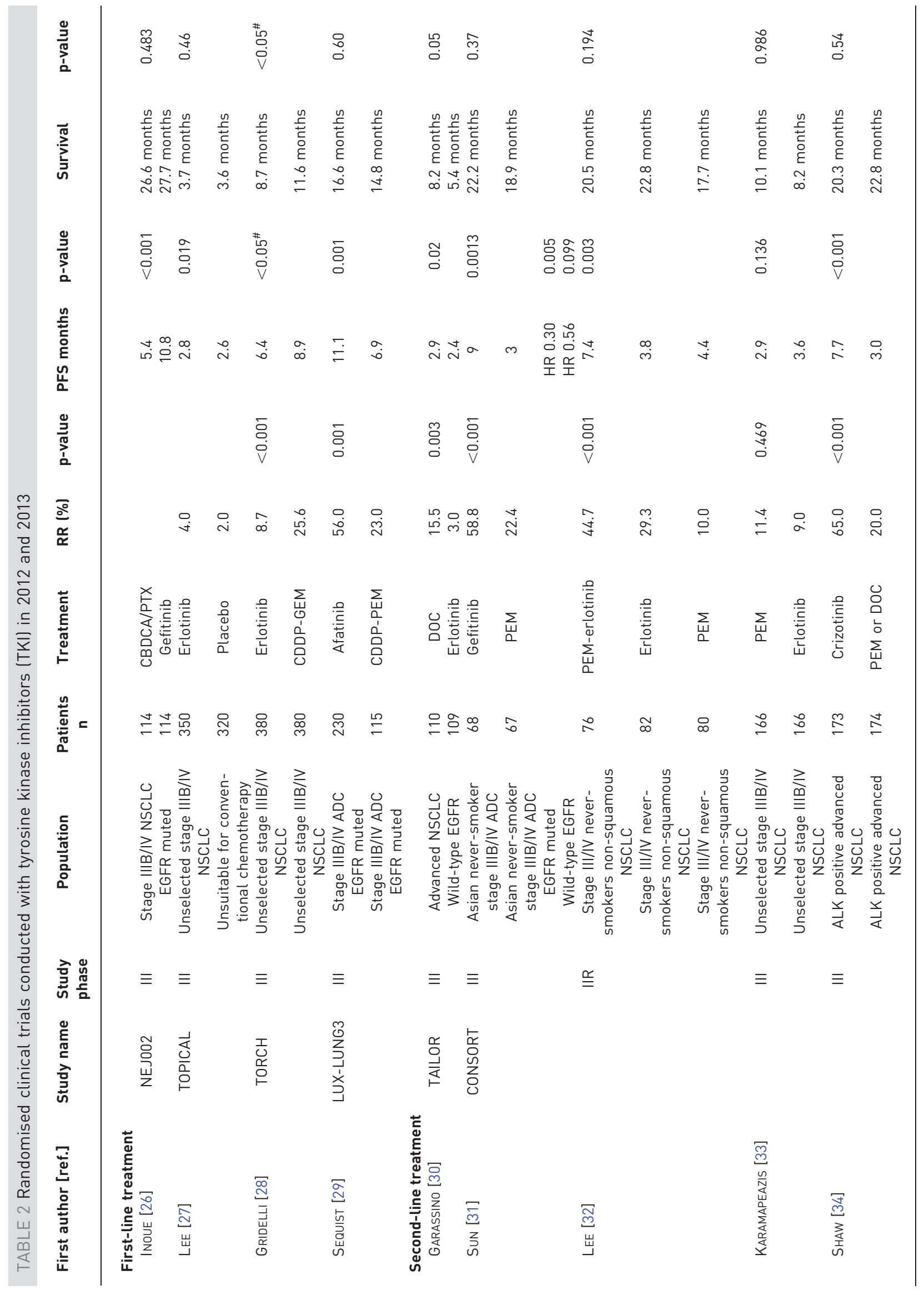




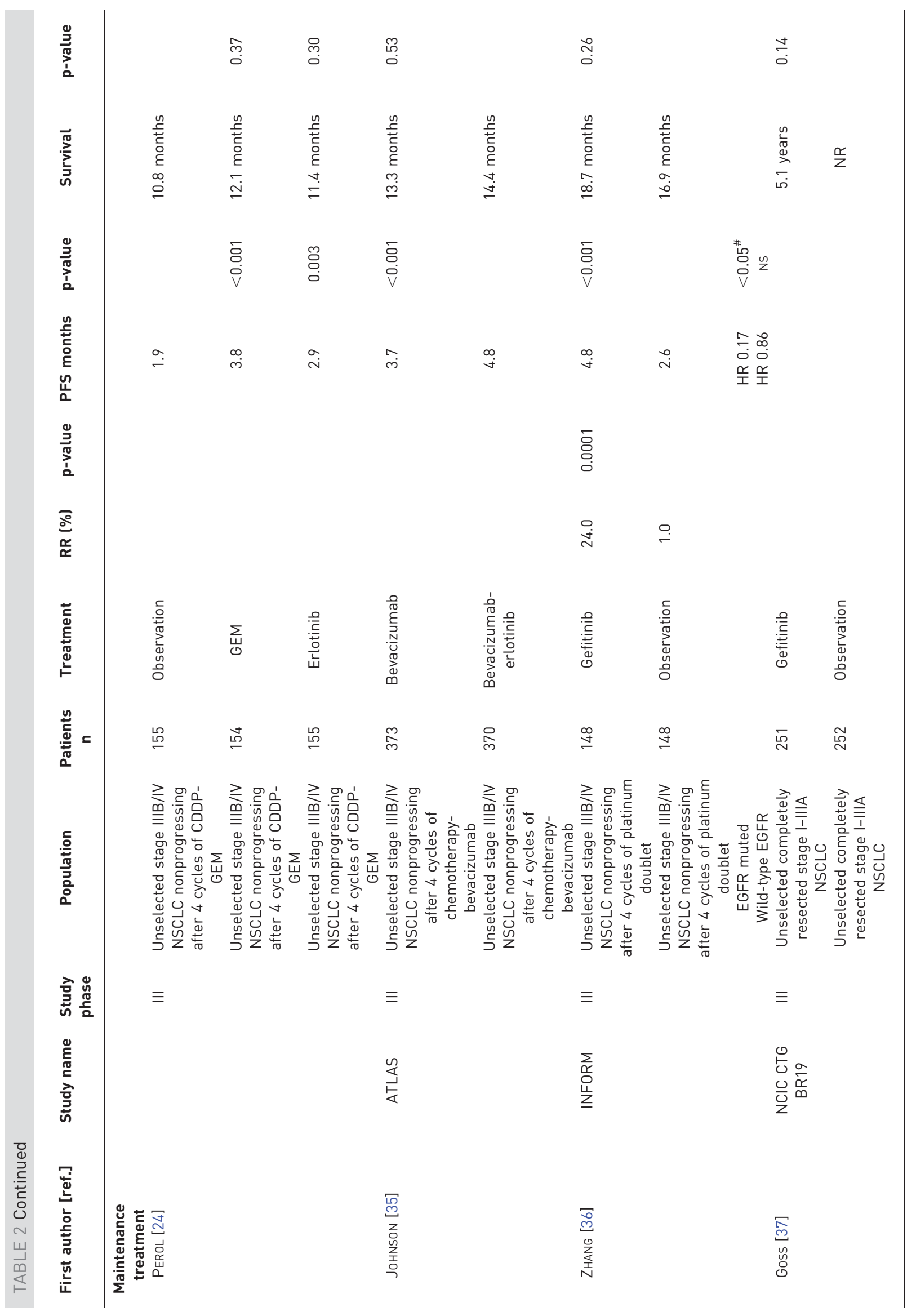




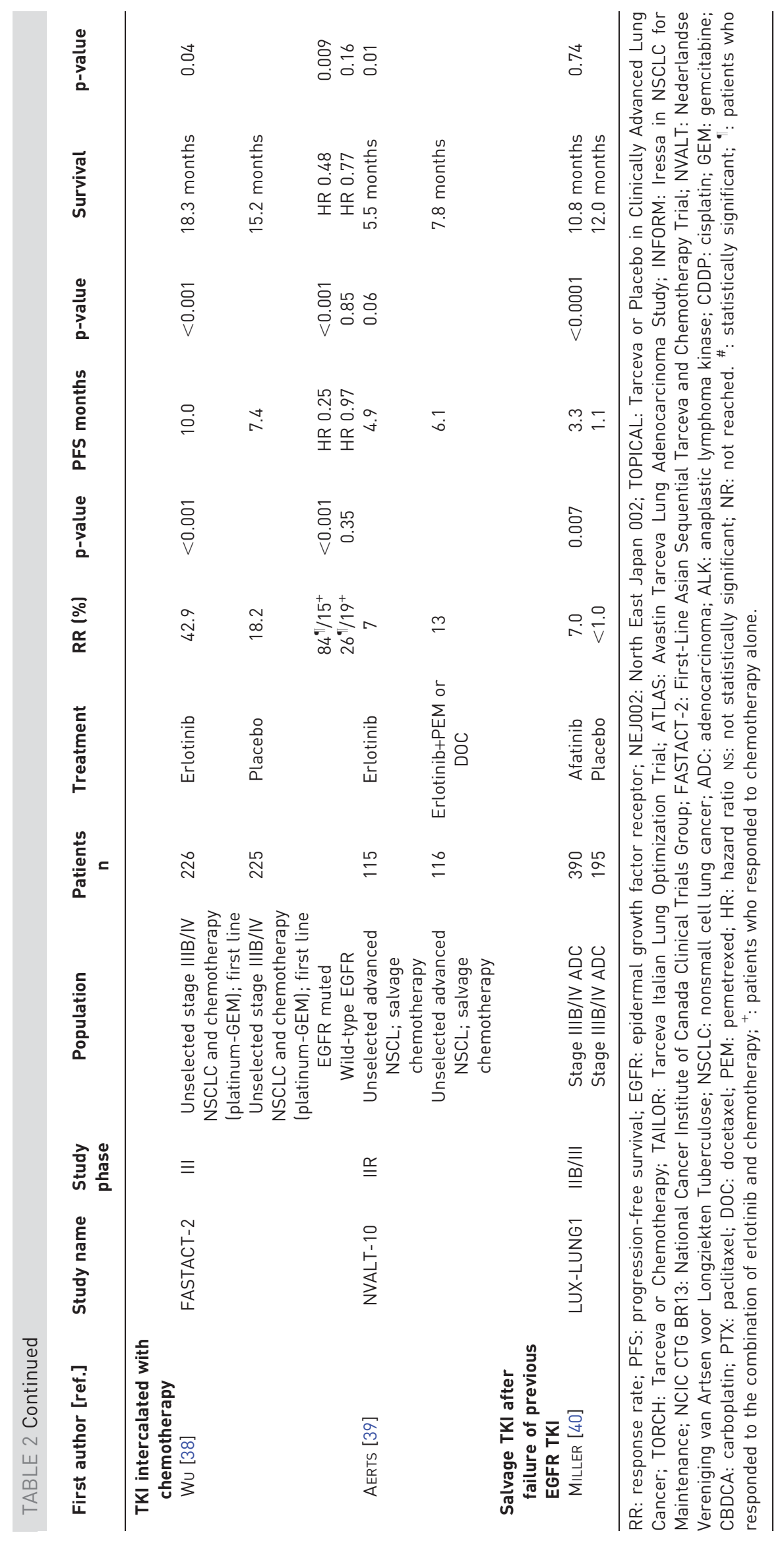


erlotinib followed at progression by cisplatin-gemcitabine was significantly inferior in terms of overall survival compared with the standard sequence of first-line chemotherapy followed by erlotinib. The TOPICAL study [27] compared placebo with first-line erlotinib in patients with advanced NSCLC who were unsuitable for chemotherapy. The results were not encouraging because there was no difference in overall survival between the two approaches. A post hoc subgroup analysis showed that patients with first-cycle rash due to erlotinib had better overall survival compared with placebo.

Crizotinib, a new TKI that has shown anti-tumour activity in the case of chromosomal rearrangements of the anaplastic lymphoma kinase $(A L K)$ gene, has been compared to chemotherapy (pemetrexed or docetaxel) as second-line therapy after failure of a prior platinum-based regimen [34]. The randomised trial showed a significantly improved response rate and progression-free survival with crizotinib.

Afatinib was tested as salvage TKI therapy after failure of a previous TKI for NSCLC with an activating EGFR mutation [40]. Control patients were treated with placebo. There was no benefit in terms of overall survival with afatinib.

\section{Small cell lung cancer treatment}

A phase III trial of concurrent thoracic radiotherapy (total dose 52.5 Gy with 2.1 Gy per fraction once a day, five times a week for five consecutive weeks) with either first- or third-cycle etoposide plus cisplatin chemotherapy for limited-disease small cell lung cancer (SCLC) has been reported by a Korean group [41]. A total of 232 patients were randomised according to a noninferiority design based on complete response as the primary end-point. The late treatment arm was not inferior to the early arm in terms of the complete response rate (early versus late: $36.0 \%$ versus $38.0 \%$ ). Median overall survival (24.1 months versus 26.8 months; HR $0.90,95 \%$ CI $0.18-1.62$ ) and median progression-free survival (12.4 months versus 11.2 months; HR 1.10 95\% CI 0.37-1.84) were not different between the two arms. Neutropenic fever occurred more commonly in the early arm $(21.6 \%$ versus $10.2 \%$; $=0.02)$. The authors concluded that late chemoradiotherapy is not inferior to early chemoradiotherapy.

In extensive disease, the final results of a German-Austrian randomised trial comparing topotecan plus cisplatin $(n=358)$ and cisplatin plus etoposide $(n=345)$ as first-line treatment have failed to show statistically significant difference in survival [42]. The median overall survival was 44.9 weeks in the topotecan group and 40.9 weeks in the etoposide group with a HR of 0.92 (95\% CI 0.78-1.08, p=0.30). Thus, this study reinforces the platinum derivative plus etoposide doublet as a recommended chemotherapy regimen for first-line treatment of SCLC.

The roles of cisplatin and carboplatin in first-line chemotherapy of SCLC were assessed in the COCIS metaanalysis of individual patient data [43]. Four eligible trials with 663 patients (328 assigned to cisplatin and 335 to carboplatin) were included in the aggregation. Median overall survival was 9.6 months for cisplatin and 9.4 months for carboplatin (HR 1.08, 95\% CI 0.92-1.27; $\mathrm{p}=0.37$ ). There was no evidence of treatment difference between the cisplatin and carboplatin arms according to sex, stage, performance status or age. There was also no difference in terms of progression-free survival or objective response rate. The toxicity profile was significantly different for each of the arms: haematological toxicity (neutropenia, anaemia and thrombopenia) was higher with carboplatin, and non-haematological toxicity (neurological and renal) was higher with cisplatin.

\section{Conclusions}

The following key messages can be summarised from this clinical year in review: 1) lung cancer is becoming an increasingly important disease in females; 2) screening for lung cancer should be performed by selection based on the risk; 3) doublet chemotherapy with platinum derivatives is the standard treatment for advanced NSCLC, even in patients with poor performance status; 4) the second randomised controlled trial testing customised chemotherapy failed; and 5) two new drugs are available for targeted therapy, crizotinib and afatinib.

\section{References}

$1 \quad$ Malvezzi M, Bertuccio P, Levi F, et al. European cancer mortality predictions for the year 2013. Ann Oncol 2013; 24: 792-800.

2 Jha P, Ramasundarahettige C, Landsman V, et al. 21st-century hazards of smoking and benefits of cessation in the United States. N Engl J Med 2013; 368: 341-350.

3 Doll R, Peto R, Boreham J, et al. Mortality in relation to smoking: 50 years' observations on male British doctors. BMJ 2004; 328: 1519.

4 Thun MJ, Carter BD, Feskanich D, et al. 50-year trends in smoking-related mortality in the United States. $N$ Engl J Med 2013; 368: 351-364.

5 Brenner DR, Boffetta P, Duell EJ, et al. Previous lung diseases and lung cancer risk: a pooled analysis from the International Lung Cancer Consortium. Am J Epidemiol 2012; 176: 573-585. 
6 Hemminki K, Liu X, Ji J, et al. Effect of autoimmune diseases on risk and survival in histology-specific lung cancer. Eur Respir J 2012; 40: 1489-1495.

7 Raaschou-Nielsen O, Andersen ZJ, Beelen R, et al. Air pollution and lung cancer incidence in 17 European cohorts: prospective analyses from the European Study of Cohorts for Air Pollution Effects (ESCAPE). Lancet Oncol 2013; 14: $813-822$.

8 Bach PB, Mirkin JN, Oliver TK, et al. Benefits and harms of CT screening for lung cancer: a systematic review. JAMA 2012; 307: 2418-2429.

9 Infante M, Cavuto S, Lutman FR, et al. A randomized study of lung cancer screening with spiral computed tomography: three-year results from the DANTE trial. Am J Respir Crit Care Med 2009; 180: 445-453.

10 Aberle DR, Adams AM, Berg CD, et al. Reduced lung-cancer mortality with low-dose computed tomographic screening. N Engl J Med 2011; 365: 395-409.

11 Aberle DR, Adams AM, Berg CD, et al. Baseline characteristics of participants in the randomized national lung screening trial. J Natl Cancer Inst 2010; 102: 1771-1779.

12 Saghir Z, Dirksen A, Ashraf H, et al. CT screening for lung cancer brings forward early disease. The randomised Danish Lung Cancer Screening Trial: status after five annual screening rounds with low-dose CT. Thorax 2012; 67: 296-301.

13 Pedersen JH, Ashraf H, Dirksen A, et al. The Danish randomized lung cancer CT screening trial: overall design and results of the prevalence round. J Thorac Oncol 2009; 4: 608-614.

14 Kovalchik SA, Tammemagi M, Berg CD, et al. Targeting of low-dose CT screening according to the risk of lungcancer death. N Engl J Med 2013; 369: 245-254.

15 Travis WD, Brambilla E, Noguchi M, et al. International Association for the Study of Lung Cancer/American Thoracic Society/European Respiratory Society: international multidisciplinary classification of lung adenocarcinoma. J Thorac Oncol 2011; 6: 244-285.

16 Warth A, Muley T, Meister M, et al. The novel histologic International Association for the Study of Lung Cancer/ American Thoracic Society/European Respiratory Society classification system of lung adenocarcinoma is a stageindependent predictor of survival. J Clin Oncol 2012; 30: 1438-1446.

17 Lederlin M, Puderbach M, Muley T, et al. Correlation of radio- and histomorphological pattern of pulmonary adenocarcinoma. Eur Respir J 2013; 41: 943-951.

18 von Meyenfeldt EM, Gooiker GA, van Gijn W, et al. The relationship between volume or surgeon specialty and outcome in the surgical treatment of lung cancer: a systematic review and meta-analysis. J Thorac Oncol 2012; 7: $1170-1178$.

19 Atagi S, Kawahara M, Yokoyama A, et al. Thoracic radiotherapy with or without daily low-dose carboplatin in elderly patients with non-small-cell lung cancer: a randomised, controlled, phase 3 trial by the Japan Clinical Oncology Group (JCOG0301). Lancet Oncol 2012; 13: 671-678.

20 Boni C, Tiseo M, Boni L, et al. Triplets versus doublets, with or without cisplatin, in the first-line treatment of stage IIIB-IV non-small cell lung cancer (NSCLC) patients: a multicenter randomised factorial trial (FAST). Br J Cancer 2012; 106: 658-665.

21 Flotten $\mathrm{O}$, Gronberg BH, Bremnes R, et al. Vinorelbine and gemcitabine vs vinorelbine and carboplatin as first-line treatment of advanced NSCLC. A phase III randomised controlled trial by the Norwegian Lung Cancer Study Group. Br J Cancer 2012; 107: 442-447.

22 Zukin M, Barrios CH, Pereira JR, et al. Randomized phase III trial of single-agent pemetrexed versus carboplatin and pemetrexed in patients with advanced non-small-cell lung cancer and Eastern Cooperative Oncology Group performance status of 2. J Clin Oncol 2013; 31: 2849-2853.

23 Bepler G, Williams C, Schell MJ, et al. Randomized International phase III trial of ERCC1 and RRM1 expressionbased chemotherapy versus gemcitabine/carboplatin in advanced non-small-cell lung cancer. J Clin Oncol 2013; 31: 2404-2412.

24 Perol M, Chouaid C, Perol D, et al. Randomized, phase III study of gemcitabine or erlotinib maintenance therapy versus observation, with predefined second-line treatment, after cisplatin-gemcitabine induction chemotherapy in advanced non-small-cell lung cancer. J Clin Oncol 2012; 30: 3516-3524.

25 Paz-Ares L, De Marinis F, Dediu M, et al. Maintenance therapy with pemetrexed plus best supportive care versus placebo plus best supportive care after induction therapy with pemetrexed plus cisplatin for advanced nonsquamous non-small-cell lung cancer (PARAMOUNT): a double-blind, phase 3, randomised controlled trial. Lancet Oncol 2012; 13: 247-255.

26 Inoue $\mathrm{A}$, Kobayashi $\mathrm{K}$, Maemondo $\mathrm{M}$, et al. Updated overall survival results from a randomized phase III trial comparing gefitinib with carboplatin-paclitaxel for chemo-naïve non-small cell lung cancer with sensitive EGFR gene mutations (NEJ002). Ann Oncol 2013; 24: 54-59.

27 Lee SM, Khan I, Upadhyay S, et al. First-line erlotinib in patients with advanced non-small-cell lung cancer unsuitable for chemotherapy (TOPICAL): a double-blind, placebo-controlled, phase 3 trial. Lancet Oncol 2012; 13: $1161-1170$.

28 Gridelli C, Ciardiello F, Gallo C, et al. First-line erlotinib followed by second-line cisplatin-gemcitabine chemotherapy in advanced non-small-cell lung cancer: the TORCH randomized trial. J Clin Oncol 2012; 30: 3002-3011.

29 Sequist LV, Yang JC, Yamamoto N, et al. Phase III study of afatinib or cisplatin plus pemetrexed in patients with metastatic lung adenocarcinoma with EGFR mutations. J Clin Oncol 2013; 31: 3327-3334.

30 Garassino MC, Martelli O, Broggini M, et al. Erlotinib versus docetaxel as second-line treatment of patients with advanced non-small-cell lung cancer and wild-type EGFR tumours (TAILOR): a randomised controlled trial. Lancet Oncol 2013; 14: 981-988.

31 Sun JM, Lee KH, Kim SW, et al. Gefitinib versus pemetrexed as second-line treatment in patients with nonsmall cell lung cancer previously treated with platinum-based chemotherapy (KCSG-LU08-01): an open-label, phase 3 trial. Cancer 2012; 118: 6234-6242.

32 Lee DH, Lee JS, Kim SW, et al. Three-arm randomised controlled phase 2 study comparing pemetrexed and erlotinib to either pemetrexed or erlotinib alone as second-line treatment for never-smokers with non-squamous non-small cell lung cancer. Eur J Cancer 2013; 49: 3111-3121. 
Karampeazis A, Voutsina A, Souglakos J, et al. Pemetrexed versus erlotinib in pretreated patients with advanced non-small cell lung cancer: a Hellenic Oncology Research Group (HORG) randomized phase 3 study. Cancer 2013; 119: 2754-2764.

34 Shaw AT, Kim DW, Nakagawa K, et al. Crizotinib versus chemotherapy in advanced ALK-positive lung cancer. N Engl J Med 2013; 368: 2385-2394.

35 Johnson BE, Kabbinavar F, Fehrenbacher L, et al. ATLAS: randomized, double-blind, placebo-controlled, phase IIIB trial comparing bevacizumab therapy with or without erlotinib, after completion of chemotherapy, with bevacizumab for first-line treatment of advanced non-small-cell lung cancer. J Clin Oncol 2013; 31: 3926-3934.

36 Zhang L, Ma S, Song X, et al. Gefitinib versus placebo as maintenance therapy in patients with locally advanced or metastatic non-small-cell lung cancer (INFORM; C-TONG 0804): a multicentre, double-blind randomised phase 3 trial. Lancet Oncol 2012; 13: 466-475.

37 Goss GD, O'Callaghan C, Lorimer I, et al. Gefitinib versus placebo in completely resected non-small-cell lung cancer: results of the NCIC CTG BR19 Study. J Clin Oncol 2013; 31: 3320-3326.

$38 \mathrm{Wu}$ YL, Lee JS, Thongprasert S, et al. Intercalated combination of chemotherapy and erlotinib for patients with advanced stage non-small-cell lung cancer (FASTACT-2): a randomised, double-blind trial. Lancet Oncol 2013; 14: 777-786.

39 Aerts JG, Codrington H, Lankheet NA, et al. A randomized phase II study comparing erlotinib versus erlotinib with alternating chemotherapy in relapsed non-small-cell lung cancer patients: the NVALT-10 study. Ann Oncol 2013; 24: 2860-2865.

40 Miller VA, Hirsh V, Cadranel J, et al. Afatinib versus placebo for patients with advanced, metastatic non-small-cell lung cancer after failure of erlotinib, gefitinib, or both, and one or two lines of chemotherapy (LUX-Lung 1): a phase 2b/3 randomised trial. Lancet Oncol 2012; 13: 528-538.

41 Sun JM, Ahn YC, Choi EK, et al. Phase III trial of concurrent thoracic radiotherapy with either first- or third-cycle chemotherapy for limited-disease small-cell lung cancer. Ann Oncol 2013; 24: 2088-2092.

42 Fink TH, Huber RM, Heigener DF, et al. Topotecan/cisplatin compared with cisplatin/etoposide as first-line treatment for patients with extensive disease small-cell lung cancer: final results of a randomized phase III trial. J Thorac Oncol 2012; 7: 1432-1439.

43 Rossi A, Di Maio M, Chiodini P, et al. Carboplatin- or cisplatin-based chemotherapy in first-line treatment of small-cell lung cancer: the COCIS meta-analysis of individual patient data. J Clin Oncol 2012; 30: 1692-1698. 